\title{
Erratum to: Applied Trust Leadership
}

\author{
Gus Gordon
}

\section{Erratum to: \\ Chapter 3 in: G. Gordon, Leadership through Trust, DOI 10.1007/978-3-319-56955-0_3}

The original version of the book was inadvertently published with incorrect Figure 3.2 in Chapter 3 which has to be replaced with correct figure. The erratum chapter and the book have been updated with the change.

The updated online version of this chapter can be found at http://dx.doi.org/10.1007/978-3-319-56955-0_3

(C) The Author(s) 2017

G. Gordon, Leadership through Trust, DOI 10.1007/978-3-319-56955-0_8 